ORNL/TM-2003/56

\title{
On-Line Measurements of Beryllium, Chromium, and Mercury by Using Aerosol Beam Focused Laser-Induced Plasma Spectrometer and Time-Integrated Filter Sampling Reference Method
}

\author{
M.-D. Cheng \\ R. W. Vannice
}

Environmental Sciences Division

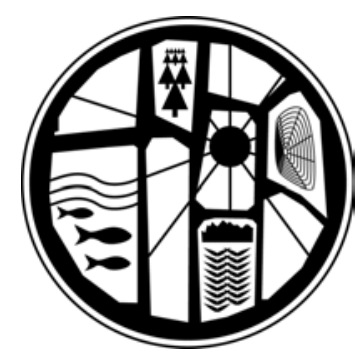




\title{
DOCUMENT AVAILABILITY
}

Reports produced after January 1, 1996, are generally available free via the U.S. Department of Energy (DOE) Information Bridge.

Web site http://www.osti.gov/bridge

Reports produced before January 1, 1996, may be purchased by members of the public from the following source.

\author{
National Technical Information Service \\ 5285 Port Royal Road \\ Springfield, VA 22161 \\ Telephone 703-605-6000 (1-800-553-6847) \\ TDD 703-487-4639 \\ Fax 703-605-6900 \\ E-mail info@ntis.fedworld.gov \\ Web site http://www.ntis.gov/support/ordernowabout.htm
}

Reports are available to DOE employees, DOE contractors, Energy Technology Data

Exchange (ETDE) representatives, and International Nuclear Information System (INIS)

representatives from the following source.

Office of Scientific and Technical Information

P.O. Box 62

Oak Ridge, TN 37831

Telephone 865-576-8401

Fax 865-576-5728

E-mail reports@adonis.osti.gov

Web site http://www.osti.gov/contact.html

This report was prepared as an account of work sponsored by an agency of the United States Government. Neither the United States Government nor any agency thereof, nor any of their employees, makes any warranty, express or implied, or assumes any legal liability or responsibility for the accuracy, completeness, or usefulness of any information, apparatus, product, or process disclosed, or represents that its use would not infringe privately owned rights. Reference herein to any specific commercial product, process, or service by trade name, trademark, manufacturer, or otherwise, does not necessarily constitute or imply its endorsement, recommendation, or favoring by the United States Government or any agency thereof. The views and opinions of authors expressed herein do not necessarily state or reflect those of the United States Government or any agency thereof. 
Environmental Sciences Division

\title{
On-Line Measurements of Beryllium, Chromium, and Mercury by Using Aerosol Beam Focused \\ Laser-Induced Plasma Spectrometer and \\ Time-Integrated Filter Sampling \\ Reference Method
}

\author{
M.-D. Cheng \\ Environmental Sciences Division \\ Oak Ridge National Laboratory \\ R. W. Vannice \\ Eastman Chemical Company \\ Kingsport, Tennessee
}

Date Published: April 2003

Prepared by

OAK RIDGE NATIONAL LABORATORY

Oak Ridge, Tennessee 37831

managed by

UT-BATTELLE, LLC

for the

U.S. DEPARTMENT OF ENERGY

under contract DE-AC05-00OR22725 



\section{CONTENTS}

\section{Page}

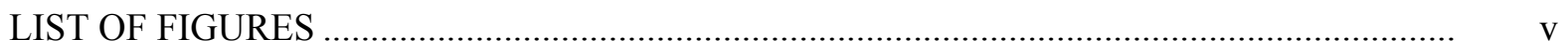

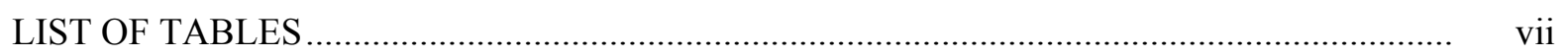

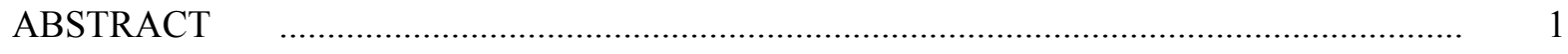

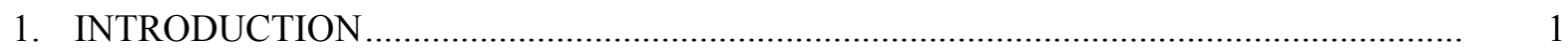

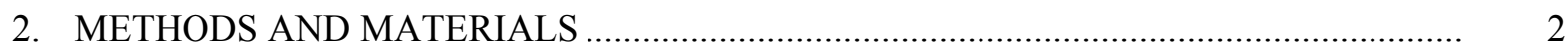

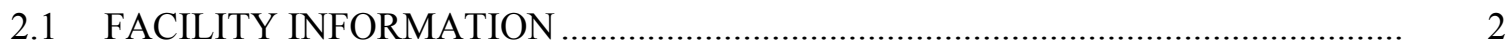

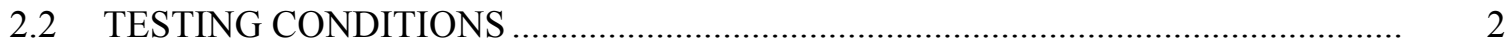

2.2.1 Aerosol Beam Focused LIPS (ABFLIPS) ................................................. 5

2.2.2 Reference Method Sampling and Analytical Procedure …................................ 7

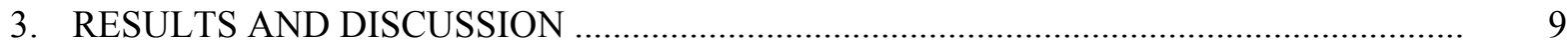

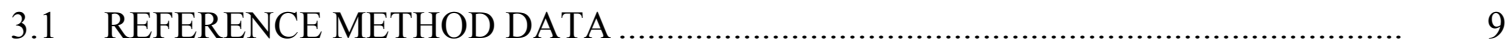

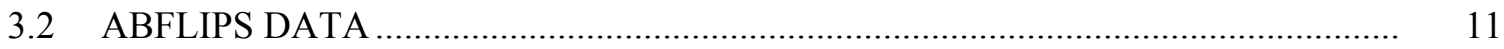

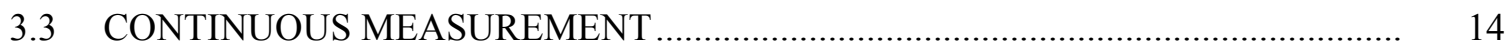

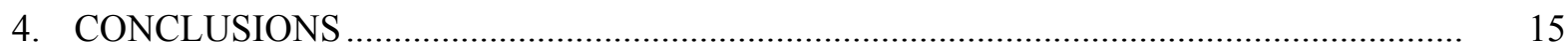

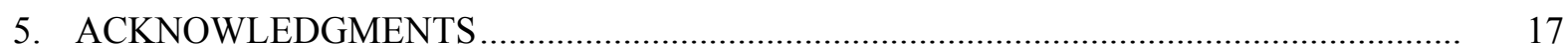

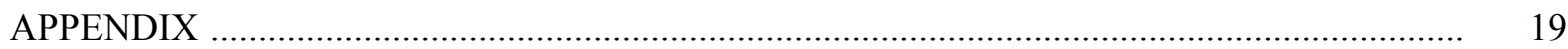





\section{LIST OF FIGURES}

Figure

Page

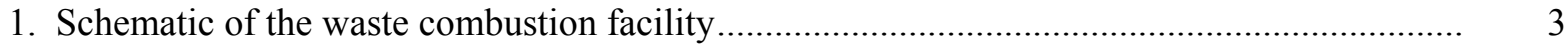

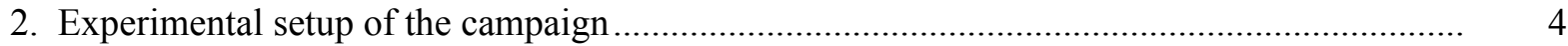

3. Schematic of the aerosol beam focusing laser-induced plasma spectroscopic cell................... 6

4. Comparison of RM and LIBS Cr data for the nine experiments........................................... 15

5. Comparison of RM and LIBS Hg data for the nine experiments.......................................... 16 



\section{LIST OF TABLES}

Table

1. Targeted and measured (denoted by*) metal solution concentrations

2. Estimated in-stack MDLs in $\mu \mathrm{g} / \mathrm{dscm}$..

3. Stack sampling and analysis methods...

4. Stack sample results

5. Summary of ABFLIPS results
Page

2

8

8

10

13 



\begin{abstract}
A novel real-time monitor for aerosol particles has been developed by the Oak Ridge National Laboratory (ORNL). The instrument is designed to perform in-situ measurement for the elemental composition of aerosol particles in flue gas. We had tested this monitor at the Eastman Chemical Company in July 2001 taking advantage of the emissions from a waste incinerator operated by the company as the background. To investigate the behavior and response of the monitor under simulated / known conditions, stock solutions of prepared metal concentration(s) were nebulized to provide spikes for the instrument testing. Strengths of the solutions were designed such that a reference method (RM) was able to collect sufficient material on filter samples that were subsequently analyzed in a laboratory to produce 30-minute average data points. Parallel aerosol measurements were performed by using the ORNL instrument. Recorded signal of an individual element was processed and the concentration calculated from a calibration curve established prior to the campaign. RM data were able to reflect the loads simulated in the spiked waste stream. However, it missed one beryllium sample. The possibility of bias exists in the RM determination of chromium that could lead to erroneous comparison between the RM and the real-time monitoring data. With the real-time detection capability, the ORNL instrument was able to reveal the emission variation by making seven measurements within a 30-minute cycle. The ability of the instrument also enables the reconstruction of the baseline chromium emission concentration. The measurements for mercury by both methods are in good agreement.
\end{abstract}

\title{
1. INTRODUCTION
}

Airborne particles or aerosols are ubiquitous in the environments. Some aerosol particles can be hazardous to human health. Controls of toxic metal-laden particles are sometimes required by the Occupational Safety and Health Administration for protection of workers. The U.S.

Environmental Protection Agency also sets standards regulating releases of toxic metals to the atmosphere through the Resource Conservation and Recovery Act (RCRA) and the Clean Air Act. In addition, interests in the ability to monitor airborne metal-laden particles in real-time in various applications have led to recent development of a field portable laser-based spectrometer. The laser-induced plasma spectroscopy (LIPS); i.e., the laser-induced breakdown spectroscopy (LIBS), has been employed in monitoring soil, alloy targets, paint pigment, metal-containing droplets, liquids, Martian rocks, and radioactive materials, for example. LIPS and LIBS will be used interchangeably in this report. The technique can be readily adapted to different sample media (solid, liquid and gas). The principle of laser-induced plasma spectroscopy was discovered more than four decades ago; however, the interest in LIPS was renewed in the early 80's. The LIPS technique does not require sample preparation, generates no analytical waste, and is fairly simple to implement in a field portable instrument.

Application of LIPS to aerosol measurement is appealing due to the merits of the technique mentioned above, but there are problems that need to be solved before the technique can be used reliably. The major problems regarding the use of LIPS in on-line aerosol measurements are sampling and calibration. Without proper sampling of aerosol particles and transport to LIPS detection, it would be unable to yield reliable and accurate measurement. In this report, a novel LIPS technique for continuous metal-laden aerosol measurement called aerosol beam focused LIPS (ABFLIPS) was field tested. The testing results of this technique on metal-spiked stack emissions (from a kiln) at a waste incineration facility are reported. The data are compared to the reference method (RM) samples taken simultaneously. 


\section{METHODS AND MATERIALS}

\subsection{FACILITY INFORMATION}

Tennessee Operations of Eastman Chemical Company operates a hazardous waste incineration complex, which includes two rotary kilns and one liquid chemical destructor at its Kingsport, Tennessee, facility. The complex is permitted to treat hazardous waste under a RCRA permit. The rotary kiln used for this testing consists of a rotary kiln incinerator, waste heat boiler, and associated air pollution control systems including a rapid quench chamber, high-energy Venturi scrubber, demister, and induced draft (ID) fan. The unit is rated at $50 \mathrm{MMBTU} / \mathrm{hr}$.

Fig. 1 is a process schematic depicting this rotary kiln. A slipstream of the stack flue gas was taken from a port downstream at the ID fan and flowed through a manifold depicted in Fig. 2. The slipstream of flue gas was spiked with metal-laden aerosols in the manifold and sampled by both the ABFLIPS and the RM sampling train. Each spiking experiment was run for 30 minutes. The system was flushed with DI-water aerosols for 5-10 minutes before the next experiment was commenced.

\subsection{TESTING CONDITIONS}

In each condition three different concentrations, three different toxic metals [chromium $(\mathrm{Cr})$, mercury $(\mathrm{Hg})$, and beryllium $(\mathrm{Be})]$ were used individually in eight out of the nine experiments. Only experiment 6 contains both $\mathrm{Cr}$ and $\mathrm{Hg}$. The spike solution concentrations of metals used in the experiments were individually shown in Table 1. It is important to remember that a $1,000 \mu \mathrm{g}$ $\mathrm{mL}^{-1}$ solution of a metal would not convert into metal-laden aerosol concentration that has metal concentration equal to $1,000 \mu \mathrm{g} \mathrm{mL}^{-1}$ of air. The exact metal concentration in the air tends to be smaller, due to mass transfer limitation, and needs to be determined experimentally.

Table 1. Targeted and measured (denoted by *) metal solution concentrations

(in $\mu \mathrm{g}$ of the target metal $/ \mathrm{mL}$ of the solution)

\begin{tabular}{rrrrrrr}
\hline$\#$ & $\mathrm{Cr}$ & $\mathrm{Hg}$ & $\mathrm{Be}$ & $\mathrm{Cr}^{*}$ & $\mathrm{Hg}^{+}$ & $\mathrm{Mg}^{*}$ \\
\hline 1 & 1 & 0 & 0 & 1.05 & $\mathrm{NA}$ & $\mathrm{NA}$ \\
2 & 100 & 0 & 0 & 90 & 0.093 & NA \\
3 & 1000 & 0 & 0 & 937 & 0.19 & NA \\
4 & 0 & 1 & 0 & 0 & 1.45 & NA \\
5 & 0 & 1000 & 0 & 0 & 1200 & NA \\
6 & 60 & 20 & 0 & 70 & 35 & 492 \\
7 & 0 & 0 & 1000 & 0 & NA & NA \\
8 & 0 & 0 & 50 & 0 & NA & NA \\
9 & 0 & 0 & 2.5 & 0 & NA & NA \\
\hline
\end{tabular}

*Inductively Coupled Plasma (ICP)-Mass Spectroscopy (MS) verification done after the campaign.

+ Cold Vapor Atomic Absorption analysis for total mercury done after the campaign.

NA indicates no analysis data. Postal analysis of the solution was intended to verify the metal concentration stability of the stock solution. 


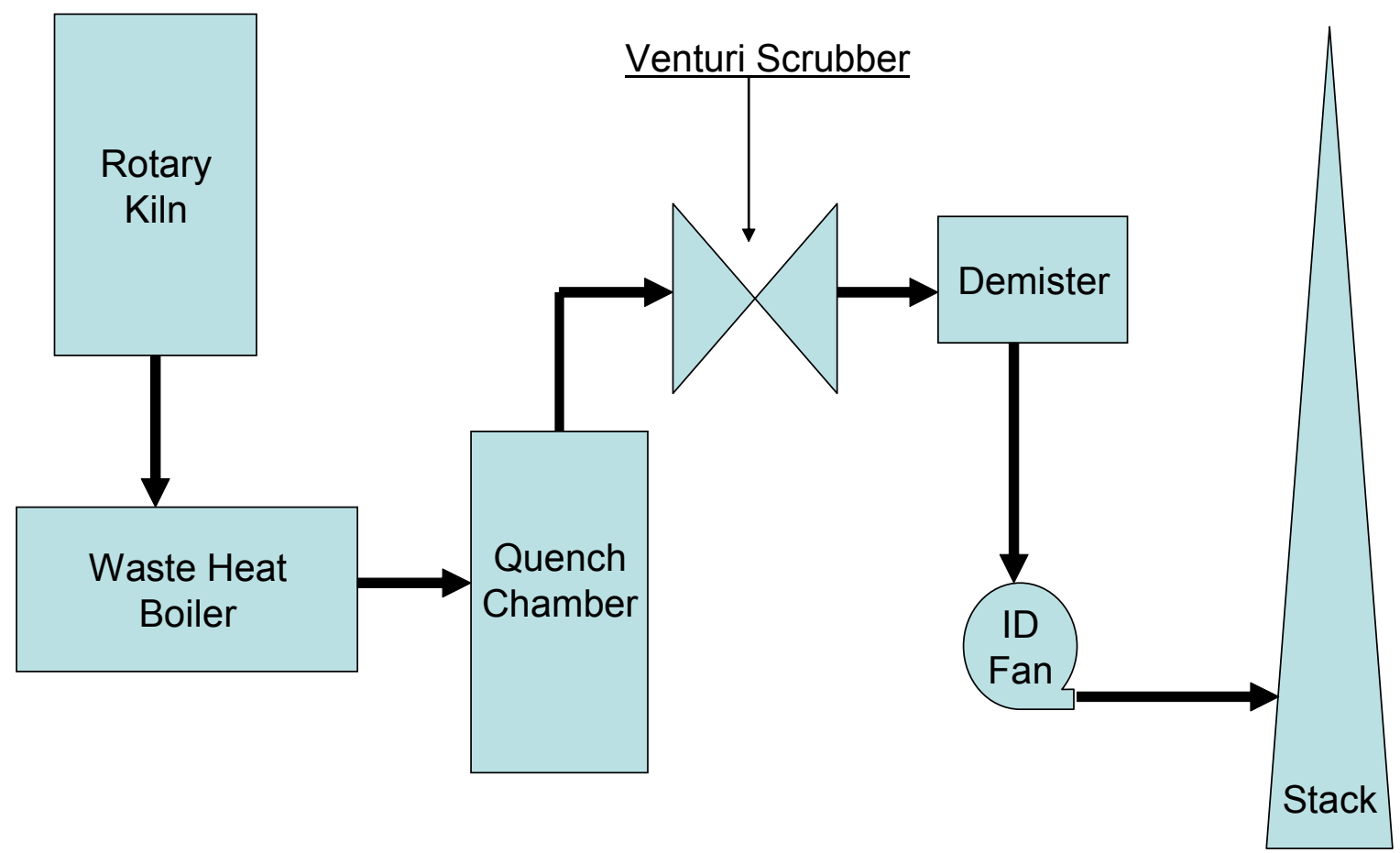

Fig. 1. Schematic of the waste combustion facility. Shown also is the flow of waste stream from the combustor (kiln) to the stack. 


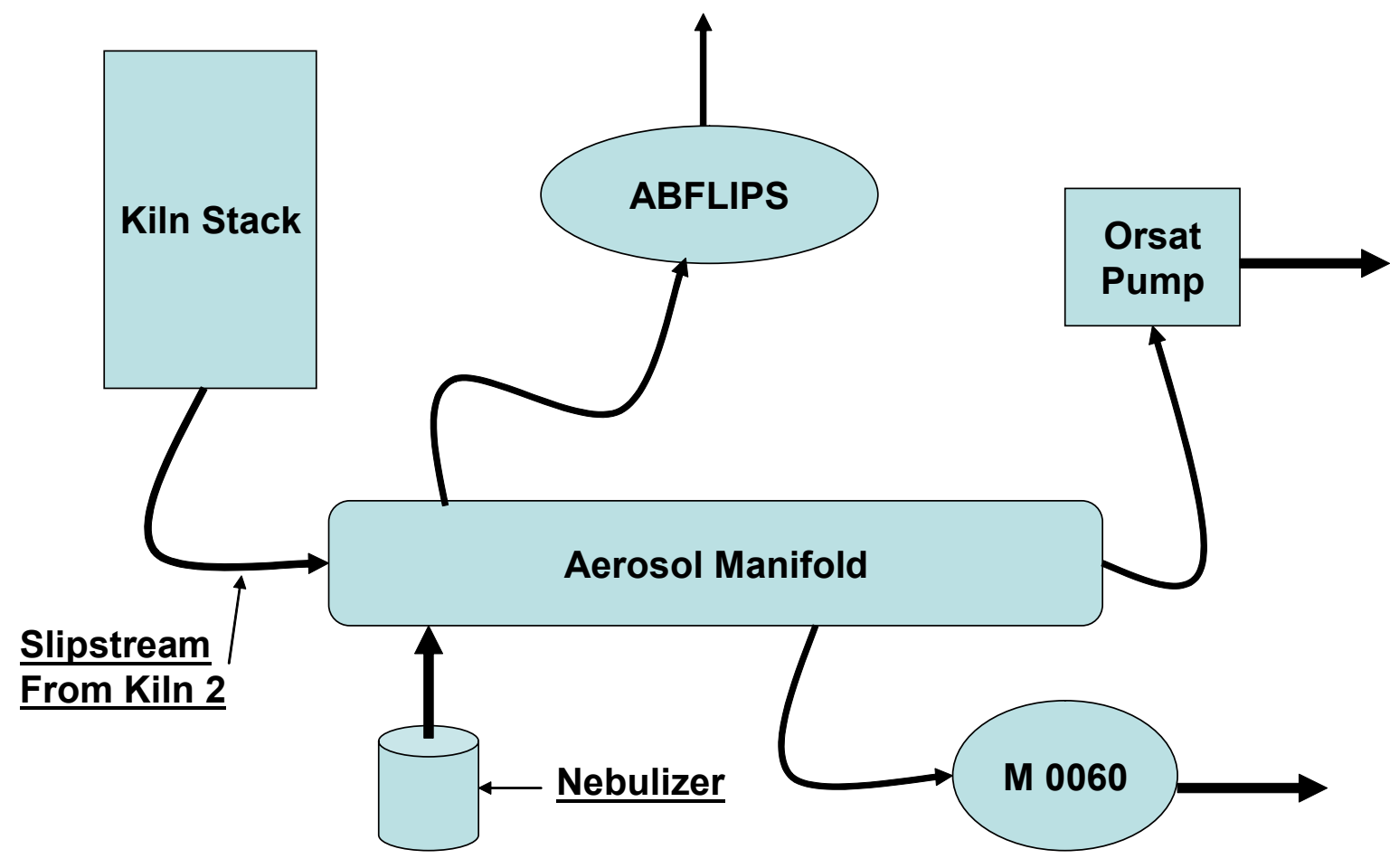

Fig. 2. Experimental setup of the campaign. Flue gas was slipstream samples from the stack into an aerosol manifold where metal-laden aerosols were spiked. ABFLIPS and RM sampling were done at the manifold. 
The chromium solutions were prepared by dissolving pre-determined amounts of reagent-grade $\mathrm{CrCl}_{3}$ salt into 1-L DI water. The $\mathrm{Hg}$ solutions were prepared by dissolving reagent-grade $\mathrm{HgCl}_{2}$ salt of known amounts into 1-L DI water, while the Be solution was used as it was purchased from Leeman Labs, Inc. (Lot \# 409805 Plasma Pure grade). The Be stock solution was 1,000 $\mu \mathrm{g}$ $\mathrm{mL}^{-1}$ in $5 \% \mathrm{HCl}$ and $1 \% \mathrm{HNO}_{3}$ stock in a $500-\mathrm{mL}$ plastic bottle, and was prepared from beryllium acetate salt.

Spiking the flue slipstream was conducted in the following manners. Aerosol particles were nebulized from the prepared solutions with particle-free air. The flow rate of aerosol from the nebulizer was measured to be $2 \pm 0.2$ liters per minute $\left(\mathrm{L} \mathrm{m}^{-1}\right)$. The manifold spiking set up is useful in the instrument evaluation phase because of its simplicity and convenience to operate with reasonably good precision. One can also take the advantage of the actual flue gas background to investigate its impacts on the instrument performance as well as establishing analytical merits.

The particles generated by the nebulizer typically have a peak diameter around $0.3 \mu \mathrm{m}$ measured by using a scanning mobility particle size (SMPS ${ }^{\circledR}$ ) at ORNL before the campaign was conducted. The largest particles produced by this technique generally are smaller than $0.7 \mu \mathrm{m}$, the size distribution was assumed to be unchanged in the field when the air pressure was operated identically to that used at the lab. We have extensive experience with the use of the nebulizer in generating aerosols from prepared solutions, and found that by holding the input pressure to the nebulizer relatively constant the size distribution is reproducible.

Fig. 2 shows the setup of the field experiment. The slipstream flue gas was drawn into the cylindrical PVC manifold of 5.1-cm internal diameter (ID), while the sampling ports on the manifold were fitted with $0.64-\mathrm{cm}$ stainless steel connectors. The connector was protruded into the manifold for $1.27-\mathrm{cm}$ to enable sampling at the center of the manifold. The $2 \mathrm{~L} \mathrm{~m}^{-1}$ aerosol flow was added to the stack exhaust that was drawn into the manifold at a flow rate of 30-40 L

$\mathrm{m}^{-1}$. The total flow rate would drive approximately $33 \mathrm{~cm} \mathrm{~s}^{-1}$ linear face velocity through the cylindrical manifold. The total residence time inside the manifold at the linear velocity was $3.7 \mathrm{~s}$. Even distribution of flow inside the manifold was aided upfront by using a plastic mesh laminarizer.

The moisture contents in the waste stream measured for the nine experiments were in the range of $0.62 \%$ to $4.65 \%$ by volume indicating a reasonably dry gas condition in the aerosol manifold. Thus, moisture was not considered as a serious interference in the experiments.

\subsubsection{Aerosol Beam Focused LIPS (ABFLIPS)}

The ABFLIPS technique employed here in the testing is a hybridization of aerosol technology and laser-induced plasma spectroscopy. The schematic of the ABFLIPS technique is shown in Fig. 3. Aerosols are drawn into the LIPS system at a volumetric flow rate of $5 \mathrm{~L} \mathrm{~min}^{-1}$ by using a vacuum pump that is operated at slightly lower than one atmospheric pressure and subsonic condition. Aerosol particles drawn into a shaped nozzle are forced to the center line of the flow stream before they are focused to a small spot (e.g., a focal point) at a distance 1-2 mm from the nozzle exit. As a result the particle number at the focal point is increased. When a laser pulse arriving from a perpendicular direction (also perpendicular to the drawing) intercepts the particles at the focal point of the aerosol beam, a significant reduction in the optical breakdown threshold occurs. 
The laser used in this work emitted green light (of 532-nm wavelength) and pulsed at approximately $10 \mathrm{~Hz}$ ( 1 shot in every $100 \mathrm{~ms}$ ) with a $5 \mathrm{~ns}$ pulse length. The laser energy fluctuation was found to be $\pm 2 \%$ measured by a Moletron power meter before the campaign was conducted. The laser energy was adjusted such that no plasma was formed when aerosol particles were absent that was done by adding a HEPA filter at the inlet of the ABFLIPS during the adjustment. If the laser energy remains unchanged, the optical breakdown threshold is reduced by the presence of particles leading to plasma formation. The plasma vaporizes the particles and activates the metals embedded in the aerosol particles.

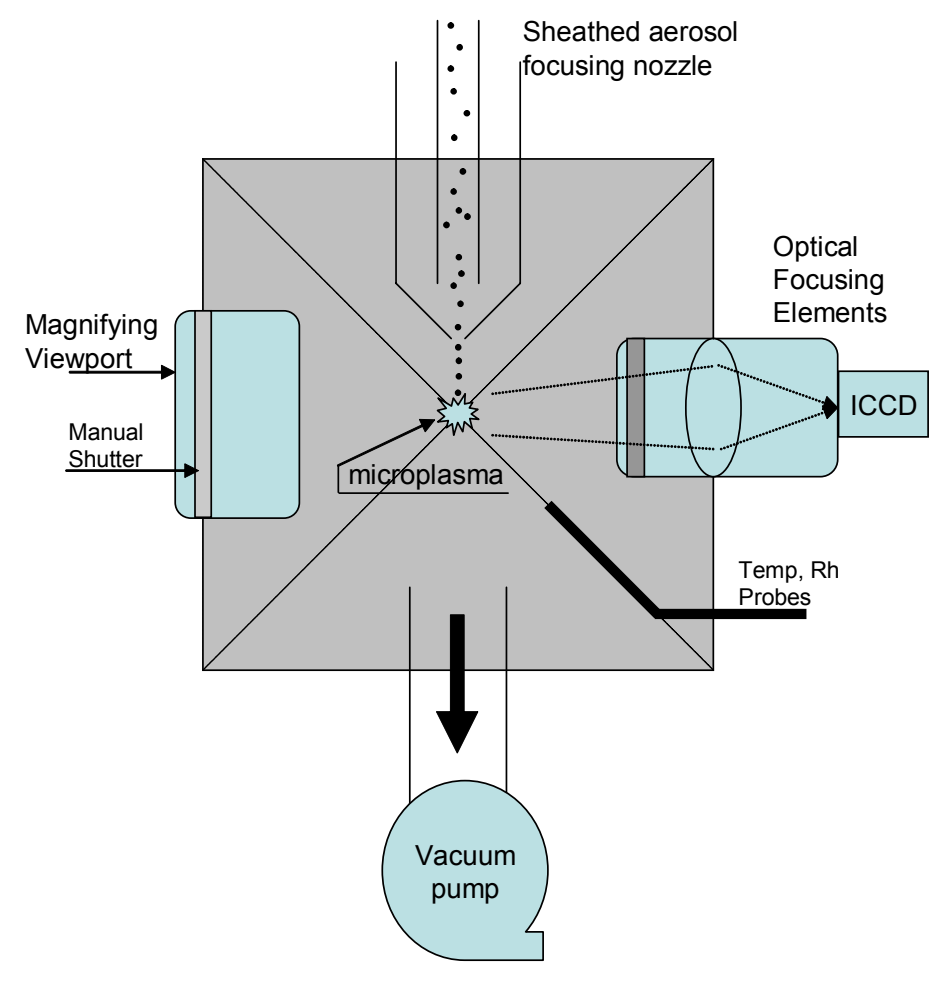

Fig. 3. Schematic of the aerosol beam focusing laser-induced plasma spectroscopic cell.

As the laser pulses, the plasma disappears intermittently; the time-gated emission measurement is performed by using an intensified charge-coupled array device (ICCD) that records the emission light intensity as a function of pixel location. A computerized grating is used to calibrate pixel locations and converts them into wavelengths. Emission light was collected via a lens array and fiber optics cable and transmitted to a portable computer where the signals were processed. The optical receiving configuration permits good optical transmission from $190 \mathrm{~nm}$ to $680 \mathrm{~nm}$.

The intensely bright light produced at the time the plasma was ignited creates broadband background emissions. The ICCD observation is gated to avoid the background light produced from gaseous molecules (such as oxygen, nitrogen and organic compounds) in the carrier matrix, because the background light decays much faster than the signals from the target analytes. The time gating for reducing the background emission light is necessary to increase the signal-to- 
noise ratio and enhance aerosol metal signals. Once a line is identified, it is evaluated with a 4-parameter Lorentzien model; the model estimated peak of each line was compared with the National Institute of Science and Technology \#38 spectral library to identify the peaks.

Quantitative determination was done via a calibration curve established previously in the lab (for $\mathrm{Hg}$ and $\mathrm{Cr}$ only) before the field experiments. The model estimated signal/readout was used to calculate the target species concentration in $\mu \mathrm{g}$ of the analyte metal per actual $\mathrm{m}^{-3}$ of sampled air volume.

ABFLIPS measurement for an element $(\mathrm{Cr}, \mathrm{Hg}$, or $\mathrm{Be})$ was obtained on a 25 -second cycle; i.e., 250 shots from the laser firing at $10-\mathrm{Hz}$ pulse rate. A total of approximately 3 minutes was required to perform measurements for the three elements at their selected wavelength regions characteristic to the elements for each measurement. Seven 3-minute measurements were made resulting in a total of $21(=7 * 3)$ ABFLIP data points for each experimental condition. The laser firing was stopped after 21 minutes in each 30-minute experimental cycle while the aerosol generation and RM sampling were continued for the rest of the 9 minutes. All ABFLIPS data analyses were performed after the nine experiments were completed at the Eastman facility.

\subsubsection{Reference Method Sampling and Analytical Procedure}

Particles produced by the nebulizer were sampled at $18 \mathrm{~L} \mathrm{~min}^{-1}$ by a modified reference method 0060 sampling train downstream of the ABFLIPS sampling port (see Fig. 2). No isokinetic sampling was performed because the small spiked particles were expected to follow the streamline of sampling airflow reasonably well. Minimal lost of the particles by impaction on the sampling probe was expected. In addition, a heated sampling probe was not used. The sampled gas was near ambient temperature. The probe length was minimized to facilitate deposition on the filters.

A table of estimated method detection limits (MDLs) for the in-stack filter sampling and analytical method is presented in Table 2. The MDLs include the analytical detection plus the sample volume. A 30-minute sampling time was used for the minimal concentrations of $1 \mu \mathrm{g} \mathrm{m}^{-3}$ assuming 3 times of the MDL for an element is the smallest concentration detectable. Chromium with its MDL of $0.76 \mu \mathrm{g} \mathrm{m}^{-3}$ was the exception among the 3 elements interested, because a 30 minute sampling time would require a minimal $\mathrm{Cr}$ amount to be $2.28 \mu \mathrm{g} \mathrm{m}^{-3}$. The filter samples were collected and analyzed by Eastman personnel (see the Acknowledgement Section) performing the sampling and analysis procedures shown in Table 3.

Nine separate sampling runs were completed for the test project. Both field and reagent blanks were taken and analyzed. Contamination of mercury and chromium were found in both sets of blanks. Prior to calculating metals concentrations in the gas, the quantities found in the reagent blanks (not the field blanks) were subtracted from the quantities found in the spiked stack samples following Method 0060 procedures. 
Table 2. Estimated in-stack MDLs in $\mu \mathrm{g} / \mathrm{dscm}$ (micrograms per dry standard cubic meter)

\begin{tabular}{cc}
\hline Sampling time & $30 \mathrm{~min}$ \\
\hline Beryllium $(\mathrm{Be})$ & 0.15 \\
Chromium $(\mathrm{Cr})$ & 0.76 \\
Mercury $(\mathrm{Hg})$ & 0.28 \\
\hline
\end{tabular}

Assumptions: $0.6 \mathrm{scfm}$ or $28.3 \mathrm{~L} \mathrm{~min}^{-1}$ sampling rate; $12 \%$ volume moisture;

Analytical MDLs: $\mathrm{Cr}=1 \mu \mathrm{g} / \mathrm{L} ; \mathrm{Be}=0.2 \mu \mathrm{g} / \mathrm{L}$; $\mathrm{Hg}=0.02 \mu \mathrm{g} / \mathrm{L}$ of solution.

Table 3. Stack sampling and analysis methods

\begin{tabular}{llll}
\hline \multicolumn{1}{c}{ Analyte } & $\begin{array}{c}\text { Sampling } \\
\text { method }\end{array}$ & $\begin{array}{c}\text { Analytical } \\
\text { method }\end{array}$ & \multicolumn{1}{c}{ Comments } \\
\hline $\mathrm{Cr}, \mathrm{Be}$ & ${\mathrm{M} 0060^{*}}^{*}$ & $6010 \mathrm{~B}^{*}$ & No need to sample isokinetically \\
$\mathrm{Hg}$ & ${\mathrm{M} 0060^{*}}^{*}$ & $7471 \mathrm{~A}^{*}$ & No need to sample isokinetically \\
Moisture & $\mathrm{M}^{* *}$ & $\mathrm{M}^{* *}$ & $\begin{array}{l}\text { Needed to correct concentrations for } \\
\text { moisture. Single point. }\end{array}$ \\
\hline
\end{tabular}

*Test Method for Evaluating Solid Waste, Physical/Chemical Method (SW-864), $3^{\text {rd }}$ ed.

**40 CFR60, Appendix A, July 1, 1997. 
The stack gas was near ambient temperature, so an unheated probe was specified; the filter was heated to $120^{\circ} \mathrm{C}$, to prevent condensation on the filter. Recovery and digestion of the stack samples was performed according to Method 0060, while analysis was performed by Methods 6010B (Be and $\mathrm{Cr}$ ) and 7470A ( $\mathrm{Hg})$. Validation of the digestion and analysis of the Inductively Coupled Plasma (ICP) metals (Be and $\mathrm{Cr}$ ) consists of calibration blanks, calibration verifications, duplicates, analysis of quality control check samples, and post-digestion spike recoveries. For the mercury analysis, the validation measure is a post-digestion spike recovery. All of these measures were found to be within specifications.

\section{RESULTS AND DISCUSSION}

\subsection{REFERENCE METHOD DATA}

Test results for the nine experimental runs were shown in Table 4. Cr was identified at all samples including those spiking solutions (experiments 4, 5, 7, 8 and 9) that $\mathrm{Cr}$ was absent. $\mathrm{Cr}$ identified in these solutions was attributed to the background flue gas. The Be solution was fresh; however, the $\mathrm{Cr}$ and $\mathrm{Hg}$ solutions were prepared 9 months before the experiments and stored in Naglene bottles under room temperature and dark conditions. The solutions were analyzed for $\mathrm{Cr}$ and $\mathrm{Hg}$ by ICP-MS at ORNL after the campaign to verify the strengths of the aged solutions. The results are shown in the last two columns of Table 1. There was minute degradation in the strengths. The ICP-MS Cr data indicate that the prepared metal concentrations were not significantly affected by storage. Similarly, mercury solution data obtained by using the cold vapor atomic absorption analysis indicate that the prepared solutions were not significantly affected by storage.

Sets 1-3. The 30-minute RM Cr data for the first three experiments were $0.282,13.0$ and $165 \mu \mathrm{g}$ $\mathrm{m}^{-3}$, respectively. Note that the solution chromium concentrations were targeted at 1 (determined as 1.05 by ICP-MS), 100 (90 by ICP-MS), and 1000 (937 by ICP-MS) ppmw. The "effective nebulization efficiencies $(\xi)$ " represented by the ratios of aerosol $\mathrm{Cr}$ concentration to the measured solution $\mathrm{Cr}$ concentration are $27 \%, 14 \%$ and $18 \%$ for experiments 1,2 and 3 , respectively. Post-analysis of $\mathrm{Hg}$ for the $\mathrm{Cr}$ solutions 2 and 3 indicates the levels of $\mathrm{Hg}$ were 0.093 and $0.19 \mathrm{ppmw}$ ( or $\mu \mathrm{g} / \mathrm{mL}$ ), respectively. The $\xi$ values calculated for these two solutions using these $\mathrm{Hg}$ data were $9.6 \%(=0.093 / 0.97)$ and $32 \%(=0.19 / 0.59)$, which are less reliable because of the uncertainties associated with the $\mathrm{Hg}$ measurements and the nebulization. If we use the $\mathrm{Cr} \xi$ for these two sets (i.e., $14 \%$ and $18 \%$ ), we estimated the aerosol mercury concentrations to be 0.013 for \# 2 and $0.033 \mu \mathrm{g} \mathrm{m}^{-3}$ for \#3, respectively. The RM mercury concentration was 
Table 4. Stack sample results

\begin{tabular}{|c|c|c|c|c|c|c|c|c|c|}
\hline Run & 1 & 2 & 3 & 4 & 5 & 6 & 7 & 8 & 9 \\
\hline Date & $7-17-02$ & $7-17-02$ & $7-17-02$ & $7-17-02$ & $7-17-02$ & $7-18-02$ & $7-18-02$ & $7-18-02$ & $7-18-02$ \\
\hline Start Time & $9: 30$ & $10: 15$ & $11: 05$ & $12: 00$ & $12: 45$ & $08: 25$ & $09: 15$ & $10: 15$ & $11: 05$ \\
\hline Finish Time & $10: 00$ & $10: 45$ & $11: 35$ & $12: 30$ & $13: 15$ & $08: 55$ & $09: 45$ & $10: 45$ & $11: 35$ \\
\hline Sampled Volume, dscf & 19.91 & 21.10 & 21.79 & 20.81 & 20.69 & 21.06 & 21.14 & 21.19 & 21.24 \\
\hline Moisture, \% vol. & 0.64 & 0.62 & 2.22 & 2.19 & 2.64 & 4.65 & 4.14 & 4.58 & 3.73 \\
\hline \multicolumn{10}{|l|}{ Metals Results } \\
\hline $\mathrm{Be}, \mu \mathrm{g} / \mathrm{dscm}$ & ND & ND & ND & ND & ND & ND & 56.9 & ND & 1.85 \\
\hline $\mathrm{Be}, \mu \mathrm{g} / \mathrm{scm}$ & ND & ND & ND & ND & ND & ND & 54.5 & ND & 1.78 \\
\hline $\mathrm{Cr}, \mu \mathrm{g} / \mathrm{dscm}$ & 0.28 & 13.1 & 169 & 2.41 & 0.91 & 7.86 & 4.08 & 0.23 & 4.32 \\
\hline $\mathrm{Cr}, \mu \mathrm{g} / \mathrm{scm}$ & 0.28 & 13.0 & 165 & 2.36 & 0.88 & 7.50 & 3.91 & 0.22 & 4.16 \\
\hline $\mathrm{Hg}, \mu \mathrm{g} / \mathrm{dscm}$ & 0.55 & 0.97 & 0.60 & 4.04 & 51.7 & 28.6 & 13.6 & 3.33 & 11.0 \\
\hline $\mathrm{Hg}, \mu \mathrm{g} / \mathrm{scm}$ & 0.55 & 0.97 & 0.59 & 3.95 & 50.4 & 27.2 & 13.1 & 3.18 & 10.6 \\
\hline Metals and spiking level & Low $\mathrm{Cr}$ & Medium $\mathrm{Cr}$ & High $\mathrm{Cr}$ & Low Hg & High Hg & $\begin{array}{l}\text { Medium } \mathrm{Cr} \\
\text { Medium } \mathrm{Hg}\end{array}$ & High Be & Medium Be & Low Be \\
\hline
\end{tabular}

$\mathrm{ND}=$ not detected

dscf $=$ dry standardized cubic feet at $20^{\circ} \mathrm{C}, 1 \mathrm{~atm}$.

$\mu \mathrm{g} / \mathrm{dscm}=$ micrograms per dry standard cubic meters. 
respectively measured as 0.97 and $0.59 \mu \mathrm{g} \mathrm{m}^{-3}$ for these two experiments, which are likely to be the baseline line mercury level of the Eastman flue gas. No Be was detected by the RM samples for these three experiments as was expected. Also note that the actual volume was used instead of the dry basis-converted volume as listed in Table 4, because using the actual volume would facilitate a direct comparison with ABFLIPS data that were taken under actual conditions.

Sets 4-6. In the second tri-experiment set (4, 5, and 6), no Be and $\mathrm{Cr}$ were added in spiking solutions 4 and 5. $\mathrm{Hg}$ was the only element in solutions 4 and 5, but both $\mathrm{Cr}$ and $\mathrm{Hg}$ were present in solution 6. RM data did confirm that Be was not present in the flue gas. No detectable Be signals were observed by ABFLIPS for the three experiments $(4,5$, and 6$)$ either. RM mercury concentrations resulted from the three experiments were 3.95, 50.4 and $27.2 \mu \mathrm{g} \mathrm{m}^{-3}$ reflecting the spiked $\mathrm{Hg}$ concentrations in the solutions (i.e., 1.45, 1,200 and $35 \mathrm{ppmw}$ ). The nebulizer efficiency $\xi$ estimated for $\mathrm{Hg}$ using these data were $272 \%, 4 \%$ and $78 \%$ indicating the nebulization performance was unstable. In contrast, the $\xi$ values range from $14 \%$ to $27 \%$ for $\mathrm{Cr}$. Since there was no $\mathrm{Cr}$ in these two spiking solutions (experiments 4 and 5), the $\mathrm{RM} \mathrm{Cr}$ concentrations were 2.36 and $0.88 \mu \mathrm{g} \mathrm{m}^{-3}$ should reflect the 30 -minute averaged baseline concentrations of $\mathrm{Cr}$ in the flue gas. Fluctuation of the baseline concentration over time was quite significant. In contrast, the baseline $\mathrm{Hg}$ concentrations recorded in the RM samples (1, 2 and 3 ) were relatively stable to the $\mathrm{Cr}$ concentrations. In comparison, it might be reasonable to question the contribution of the spike solution 1 , since $0.28 \mu \mathrm{g} \mathrm{m} \mathrm{m}^{-3} \mathrm{Cr}$ data obtained for experiment 1 by the $\mathrm{RM}$ was below the range of the background $\mathrm{Cr}$ concentration in the second tri-set (0.88-2.36 $\mu \mathrm{g} \mathrm{m}^{-3}$ ). Although all the concentration numbers were higher than the MDL of $\mathrm{Cr}$, there was no way we could reliably separate the spiked $\mathrm{Cr}$ signal obtained in the experiment 1 from the background $\mathrm{Cr}$ concentration based on the 30 -minute filter data.

Sets 7-9. The last tri-set data obtained in experiments 7, 8 and 9 resulted from spiking solutions containing only Be. The $\mathrm{Cr}$ data $\left(0.22-4.6 \mu \mathrm{g} \mathrm{m}^{-3}\right)$ in these three experiments appear to be in the baseline $\mathrm{Cr}$ region. However, the $\mathrm{Hg}$ levels were 13.1, 3.18, and $10.6 \mu \mathrm{g} \mathrm{m}^{-3}$ in these three experiments that are much higher than the baseline concentration of less than $1.0 \mu \mathrm{g} \mathrm{m}^{-3}$ observed in the earlier experiments. The levels are even comparable to or higher than the mercury level of experiment $4\left(3.95 \mu \mathrm{g} \mathrm{m}^{-3}\right)$. The most likely reason is that solution containing $1 \mathrm{ppmw}$ of $\mathrm{Hg}$ was unable to provide an adequate 30 -minute $\mathrm{Hg}$ signal separating from the baseline. In other words, the spike signal was too weak to be clear from the background $\mathrm{Hg}$ signal. Similar finding was obtained for the $\mathrm{Cr}$ experiment 1 . The manifold might have been contaminated after the experiments 4-6 leading to high $\mathrm{Hg}$ background level. This suggests that $\mathrm{Hg}$ should be the last target species to test in a future experiment. The Be data for experiments 7,8 , and 9 were 54.5, $\mathrm{ND}$ (not detected) and $1.78 \mu \mathrm{g} \mathrm{m}^{-3}$. The solution Be concentrations were 1000, 50, and 2.5 ppmw.

\subsection{ABFLIPS DATA}

Although the ICCD was cooled thermoelectrically to $-15^{\circ} \mathrm{C}$, background correction for each ICCD pixel was still made by subtracting the dark noise, shot-to-shot noise, and electronic readout noise from the total counts of a pixel to obtain the background corrected counts. In addition to the instrument noises mentioned above, ABFLIPS measurements were performed before the waste stream was spiked to obtain the baseline data of the three elements. In other words, we have considered an ABFLIPS measurement (denoted as $\mathrm{S}$ in the following equation) for a specific pixel (subscript i) (or calibrated to wavelength) to be resulted from: 
$S_{i}=S_{t i}+N_{i}+B_{i}$ where $S_{t i}$ is the true signal registered by a pixel, $N_{i}$ is the ensemble noise that includes the noises mentioned previously, and $\mathrm{B}_{\mathrm{i}}$ is the background count (corrected for the instrument noise $\mathrm{N}_{\mathrm{i}}$ ) at a specific wavelength. The ABFLIPS measurements performed before each spiking experiment provided data for estimating $\mathrm{B}_{\mathrm{i}}$. The $\mathrm{N}_{\mathrm{i}}$ was estimated and removed automatically when a spectrum was taken using an ICCD recording feature called the "background corrected counts."

The characteristic wavelengths chosen for the measurements were $253.65 \mathrm{~nm}$ (I) for $\mathrm{Hg}$, (425.44, 427.48 and $428.97 \mathrm{~nm}$ ) triplet (I) for Cr, and $313.04 \mathrm{~nm}$ (II) for Be. The 428.97-nm line was used for quantitative determination of $\mathrm{Cr}$ concentration. Other wavelengths such as $435.8 \mathrm{~nm}$ (I) for $\mathrm{Hg}, 467.3$ (II) and $381.5 \mathrm{~nm}$ (I) for Be were also tested during the experiments. However, the signal-to-noise ratios for the wavelengths selected here were higher than the others. Although various reasons could account for the low ratios, there is no clear-cut explanation available at the moment. The delay times for ICCD exposure were pre-programmed at $7 \mu \mathrm{s}$ for $\mathrm{Cr}, 14 \mu \mathrm{s}$ for $\mathrm{Hg}$, and $17 \mu$ s for Be. The delays times for $\mathrm{Cr}$ and $\mathrm{Hg}$ were obtained a priori at ORNL by using a technique called "kinetic profiling". The aerosol carrier gas was air in the ORNL laboratory instead of the industrial flue gas; thus, the effects of such a matrix on the delay time were possible. The gate widths were pre-programmed at $8 \mu$ s for $\mathrm{Cr}$ and $\mathrm{Hg}$, and $4 \mu \mathrm{s}$ for Be that were the times that the shutter of the ICCD was instructed to remain open and the signals were to be recorded. The gate width and the delay time were two important factors in operating the timeresolved laser-induced plasma spectroscopy.

The statistical summaries for the ABFLIPS data are presented in Table 5 that include the average, the standard deviation, the range (maximum - minimum), and the coefficient of variation (= the standard deviation/the average) for the nine experiments. The data points for an ABFLIPS statistics listed in the table are obtained from seven sequential measurements for a given experiment. A total of 189 ( $=7$ repetitions $* 3$ elements $* 9$ experiments $)$ data points were obtained.

In general, the averaged $\mathrm{Cr}$ and $\mathrm{Hg}$ values for a given experiment are in good agreement with the RM measurements. For example, the ABFLIPS averages and the RM results are statistically identical for $\mathrm{Cr}$ of experiments 2, 4, 5, 7, 8, and 9, and for all the $\mathrm{Hg}$ experiments. For $\mathrm{Hg}$, the averaged ABFLIPS measurements were statistically identical to the corresponding 30-minute integrated RM data. The coefficients of variation $(\mathrm{COV})$ for most of the nine experiments were in the tens of a percentage, higher than that for $\mathrm{Cr}$.

As for the Cr experiments 1, 3, and 6, the differences between the ABFLIPS averages and the RM measurements exist. For Cr, ABFLIPS records $12 \mathrm{X}$ higher concentration than that obtained by the \# $1 \mathrm{RM}$ sample. The ABFLIPS records range from 1.04-5.92 $\mu \mathrm{g} \mathrm{m}^{-3}$ that does not include the $\mathrm{RM}$ value of 0.28 . The $\mathrm{Cr}$ concentration during this 30 -minute time period varied significantly, $\mathrm{COV}=25 \%$, as reported by ABFLIPS. For the \#3 sample, ABFLIPS detected $40 \%$ of the RM-Cr concentration. The difference is significant; however, interestingly, the COV of Cr concentration during this 30 -minute time period is only $6 \%$. It is possible that the spike solution strength was high in the experiment 3 , overriding possible contribution from the flue gas, leading to a stationary $\mathrm{Cr}$ concentration during the 30-minute time period. Thus, the differences in experiments 1 and 3 might indicate an error in the $\mathrm{Cr}$ calibration curve established prior to the field campaign. For experiment 6 , averaged ABFLIPS Cr value was higher than (3.5X) the RM value. Again, the concentration fluctuation with this 30-minute time frame was low, $\mathrm{COV}=4 \%$, indicating stable $\mathrm{Cr}$ level. These evidences appear to reinforce the likelihood that the calibration curve for $\mathrm{Cr}$ during this campaign might be different from that established earlier. 
Table 5. Summary of ABFLIPS results

(concentrations in $\mu \mathrm{g} \mathrm{m}^{-3 \text { ) }}$

\begin{tabular}{|c|c|c|c|c|c|c|c|}
\hline Experiment & Statistics & $\mathrm{RM}-\mathrm{Cr}$ & $\mathrm{A}-\mathrm{Cr}$ & RM-Hg & $\mathrm{A}-\mathrm{Hg}$ & RM-Be & $\mathrm{A}-\mathrm{Be}$ \\
\hline 1 & $\begin{array}{l}\text { Average } \\
\text { Stand Dev } \\
\text { COV }(\%) \\
\text { Range }\end{array}$ & 0.28 & $\begin{array}{l}3.48 \\
0.88 \\
25 \% \\
2.44\end{array}$ & 0.55 & $\begin{array}{l}0.64 \\
0.11 \\
18 \% \\
0.34\end{array}$ & & \\
\hline 2 & $\begin{array}{l}\text { Average } \\
\text { Stand Dev } \\
\text { COV }(\%) \\
\text { Range }\end{array}$ & 13.0 & $\begin{array}{r}14.73 \\
1.10 \\
7 \% \\
3.35\end{array}$ & 0.97 & $\begin{array}{l}1.06 \\
0.13 \\
12 \% \\
0.37\end{array}$ & & \\
\hline 3 & $\begin{array}{l}\text { Average } \\
\text { Stand Dev } \\
\text { COV }(\%) \\
\text { Range }\end{array}$ & 165.0 & $\begin{array}{r}65.47 \\
3.74 \\
6 \% \\
10.67\end{array}$ & 0.59 & $\begin{array}{l}0.64 \\
0.22 \\
35 \% \\
0.61\end{array}$ & & \\
\hline 4 & $\begin{array}{l}\text { Average } \\
\text { Stand Dev } \\
\text { COV(\%) } \\
\text { Range }\end{array}$ & 2.36 & $\begin{array}{l}2.05 \\
0.86 \\
42 \% \\
2.37\end{array}$ & 3.95 & $\begin{array}{l}4.21 \\
0.44 \\
10 \% \\
1.00\end{array}$ & & \\
\hline 5 & $\begin{array}{l}\text { Average } \\
\text { Stand Dev } \\
\text { COV }(\%) \\
\text { Range }\end{array}$ & 0.88 & $\begin{array}{l}1.10 \\
0.32 \\
29 \% \\
0.93\end{array}$ & 50.4 & $\begin{array}{l}54.1 \\
5.50 \\
10 \% \\
15.3\end{array}$ & & \\
\hline 6 & $\begin{array}{l}\text { Average } \\
\text { Stand Dev } \\
\text { COV(\%) } \\
\text { Range }\end{array}$ & 7.50 & $\begin{array}{r}26.20 \\
1.06 \\
4 \% \\
2.97\end{array}$ & 27.2 & $\begin{array}{r}25.5 \\
3.29 \\
13 \% \\
8.37\end{array}$ & & \\
\hline 7 & $\begin{array}{l}\text { Average } \\
\text { Stand Dev } \\
\text { COV }(\%) \\
\text { Range }\end{array}$ & 3.91 & $\begin{array}{l}4.54 \\
0.60 \\
13 \% \\
1.44\end{array}$ & 13.1 & $\begin{array}{r}13.4 \\
0.51 \\
3.8 \% \\
1.46\end{array}$ & 54.5 & \\
\hline 8 & $\begin{array}{l}\text { Average } \\
\text { Stand Dev } \\
\text { COV }(\%) \\
\text { Range }\end{array}$ & 0.22 & $\begin{array}{l}0.23 \\
0.04 \\
19 \% \\
0.13\end{array}$ & 3.18 & $\begin{array}{l}3.34 \\
0.97 \\
29 \% \\
2.32\end{array}$ & & \\
\hline 9 & $\begin{array}{l}\text { Average } \\
\text { Stand Dev } \\
\text { COV }(\%) \\
\text { Range }\end{array}$ & 4.16 & $\begin{array}{l}5.13 \\
0.54 \\
11 \% \\
1.46\end{array}$ & 10.6 & $\begin{array}{l}9.32 \\
1.18 \\
13 \% \\
3.55\end{array}$ & 1.78 & \\
\hline
\end{tabular}

Note: $\mathrm{COV}=$ coefficient of variation, calculated as the ratio of standard deviation to the average value. Stand $\mathrm{Dev}=$ standard deviation. Range $=$ maximum - minimum. $\mathrm{RM}$-element $(\mathrm{Cr}, \mathrm{Hg}$, or $\mathrm{Be})$ is the $\mathrm{RM}$ measurement, A-element is the ABFLIPS measurement. 
Since data from post analysis of the solutions in Table 1 indicate that the $\mathrm{Cr}$ strengths remain little changed after several months, the quenching of $\mathrm{Cr}$ signal at 429-nm appear to be originated from the flue gas matrix during the first day of the campaign. Without additional information, it is unclear what exactly might have caused this interference. Mercury analysis using 253.7-nm appeared to be not affected by the gas matrix.

Be experiments ( 7,8 and 9) present some interesting challenges to this campaign, because a calibration curve for Be could not be established before the Eastman campaign was commenced. The Environmental Safety and Health regulations restrict researchers from generating Becontaining particles using beryllium solution at the ORNL facility. Thus, the RM data from experiments 7 and 9 were used to establish a line for calculating the Be concentration for experiment 8 . The Be concentration for experiment 8 was estimated to be $27.02 \mu \mathrm{g} / \mathrm{m}^{3}$, while the RM yielded no data for this experiment.

\subsection{CONTINUOUS MEASUREMENT}

The ability of ABFLIPS in sensing transient aerosol loadings or short-term fluctuation of metal concentration in the flue gas is clearly shown in Figs. 4-5. Fig. 4 displays the 30-minute integrated filter measurements (short horizontal bars) and the ABFLIPS Cr data (solid dots) for the nine experiments. Fig. 5 shows the mercury data for all nine experiments. Remember that $\mathrm{Cr}$ was spiked only in experiments $1,2,3$, and 6 , while only the experiments 4,5 , and 6 involve the use of Hg-containing solutions.

It appears that the $\mathrm{RM}$ data for $\mathrm{Cr}$ and $\mathrm{Hg}$ were able to follow the 30-minute transient behavior in the manifold flue gas, because the spike concentrations were calculated a priori to ensure the RM method could accumulate adequate material at the end of a 30-minute interval. In real-world situations, though, 30 minutes would not be sufficient, RM samples are taken at a much longer duration than 30-minutes. Therefore, knowledge of the variation at the incineration cannot be obtained using the RM method.

Even under controlled conditions like this field campaign, comparison of a single averaged ABFLIPS value with a single RM value would require extreme caution. The averaging times of the two methods are substantially different. This is related to the true distribution of the underlying metal concentration within the averaging time period. For a stationary time series, the Central Limit Theorem dedicates the representativeness of samples; a large number of samples are typically needed to ensure the average value would converge to the true mean. Furthermore, the RM value is not the true mean; the RM value itself is only a snap shot of concentration of the flue gas over a longer averaging time than that of ABFLIPS.

Can RM values be in error? Based on the RM mass concentrations of $\mathrm{Be}$ and $\mathrm{Hg}$ and known solution concentrations of these two metals for experiments 7 and 5, respectively, it is possible that the RM measurement for $\mathrm{Cr}$ might be biased high. Assuming the nebulization efficiency remains constant throughout the nine experiments, a reasonable assumption, the ratio of filter mass concentration for $\mathrm{Hg}$ to the solution concentration of $\mathrm{Hg}$ is about 0.05 . The ratio for $\mathrm{Be}$ is also about 0.05 . However, the ratio for $\mathrm{Cr}$ is 0.17 indicating either the $\mathrm{RM}$ measurement was biased high or the nebulization efficiency was much better for $\mathrm{Cr}$ than that for $\mathrm{Hg}$ and $\mathrm{Be}$. The nebulization efficiency is unlikely to be dependent on chemical species. Thus, the former appears to be more likely; i.e., the RM Cr measurement could be biased high. 


\section{CONCLUSIONS}

Several tests were conducted in July 2002 for a novel instrument developed by ORNL. The instrument is for in-situ real-time measurement of metal-laden aerosol particles in flue gas. Stock solutions of known metal concentration(s) were nebulized to provide spikes for the testing. Strengths of the solutions were designed such that the RM was able to take sufficient material on filters that were subsequently analyzed in a laboratory for contents of target metals $(\mathrm{Be}, \mathrm{Cr}$, and $\mathrm{Hg}$ ) to produce 30-minute average data points. Parallel continuous aerosol measurements were performed by using the ORNL instrument. Recorded optical signals of elements were analyzed and the concentration calculated based on a calibration curve established prior to the campaign.

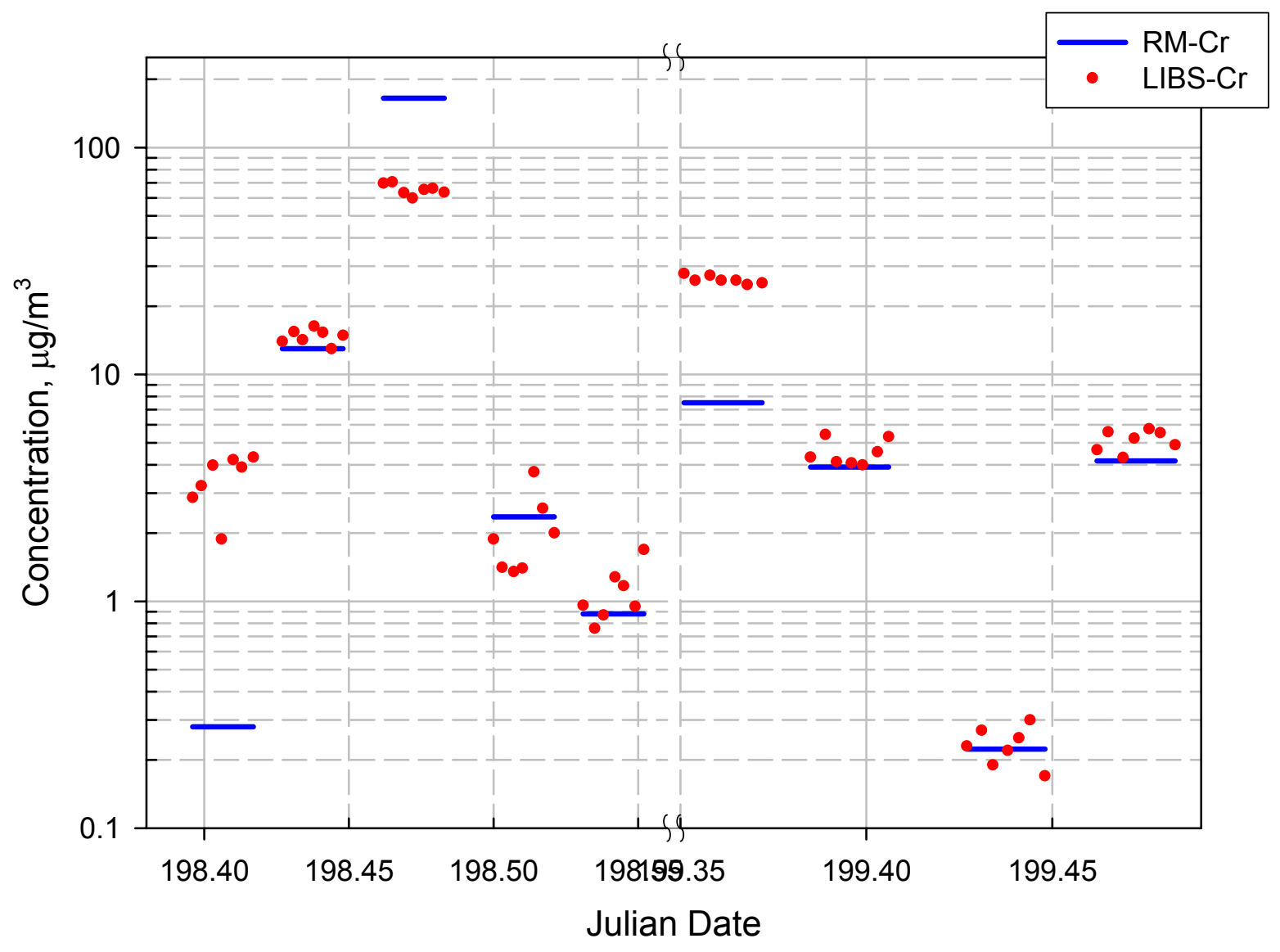

Fig. 4. Comparison of RM and LIBS Cr data for the nine experiments. 


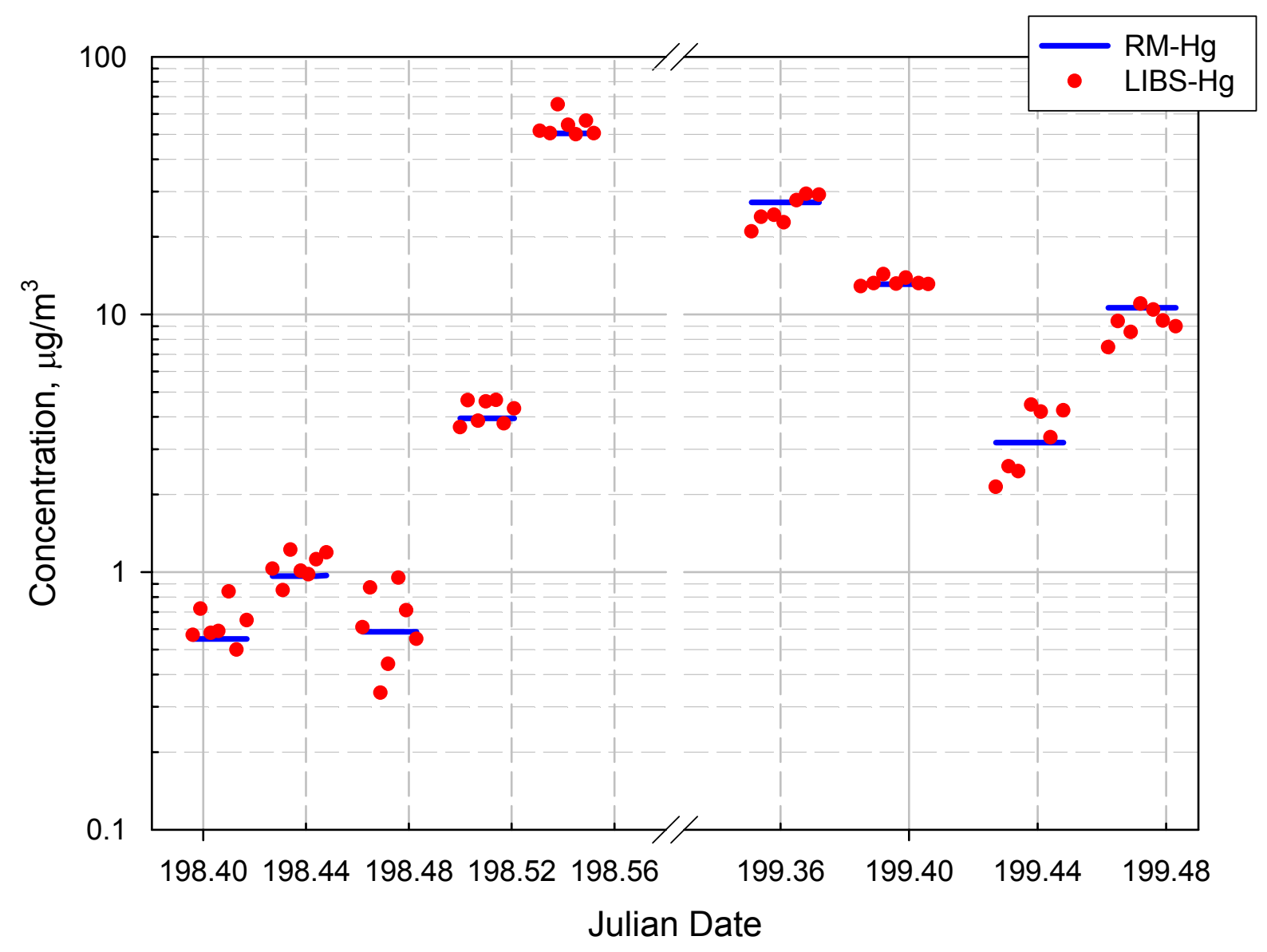

Fig. 5. Comparison of RM and LIBS Hg data for the nine experiments.

RM data reflected the pre-designed transient loads of aerosol metals in the spiked waste stream. However, it missed one beryllium sample for unclear reasons. The possibility of bias exists in the RM determination that raises a validity issue of comparing real-time measurement with timeintegrated data. With the real-time detection capability, the ORNL instrument was able to reveal the emission variation by making seven measurements within a 30 -minute cycle. The ability of the instrument also enables the reconstruction of the baseline chromium emission concentration. The measurements for mercury by both techniques appear to be in good agreement. Further improvement and development in the data analysis module, allowing on-line model analysis and chemometrics calibration, would enhance the ability of the instrument and enable it to be userfriendly. 


\section{ACKNOWLEDGMENTS}

The Strategic Environmental Research and Development Program of the Department of Defense provided the initial funding for the development of the ABFLIPS instrument concept and design. The Department of Energy Fossil Energy Office of Natural Gas and Oil Technology program and the Department of Defense Environmental Security Technology Certification Program are acknowledged for providing partial funding to this research and the field tests. The support from the Eastman waste incinerator facility and Environmental Services Laboratory, especially Frank

Fillers, Tim Hensley, Mark Ragan, and Melissa Wise are highly appreciated. Richard Strang and Janet Evans, both of the Environmental Affairs, and Brent Bacon, the waste disposal services of the Eastman Chemical Company provided excellent coordination and support. Without the dedicated personnel and generous in-kind support from the Eastman Chemical Company involved in this campaign, the authors would not be able to successfully complete the experiments as planned and scheduled. Melanie Mayes of ORNL/Environmental Sciences Division (ESD) assisted in the ICP-MS analysis of stock solutions for $\mathrm{Cr}$ and Mg. Mary Anna Bogle, also ESD, analyzed the stock solutions for mercury using Cold Vapor Atomic Absorption Spectroscopy. Comments of Gary Jacobs and Tom Early, both ORNL/ESD, were acknowledged.

The photos shown in the Appendix provide sample views of the prototype unit and the workers involved in the campaign. 

APPENDIX

SAMPLE PHOTOS TAKEN DURING THE EASTMAN CAMPAIGN 



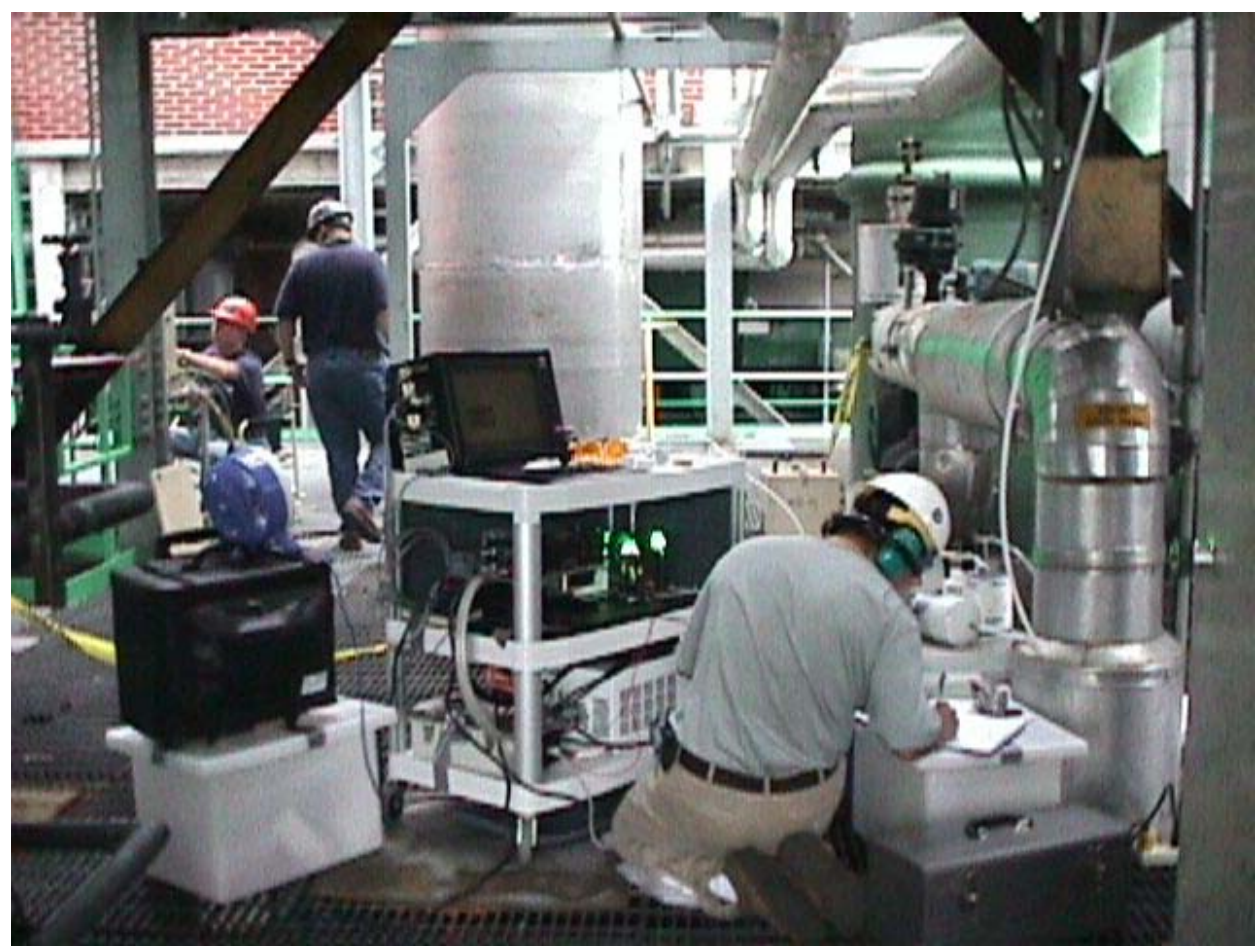

The photo shows the test surrounding at the Eastman incinerator facility. The PI took notes next to the prototype ABFLIP unit. Two Eastman staffs were present at the far back of the photo.

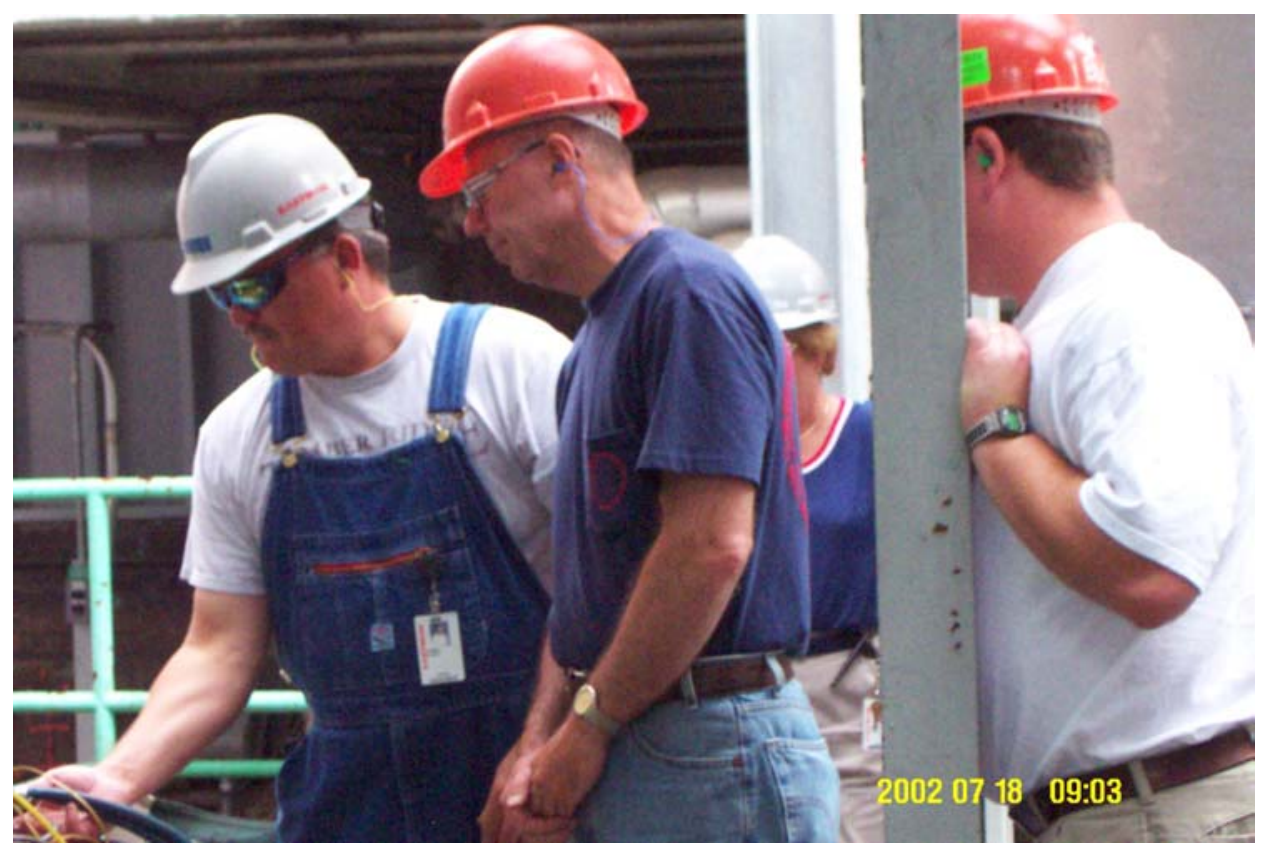

Eastman staff discussing experimental setup. 


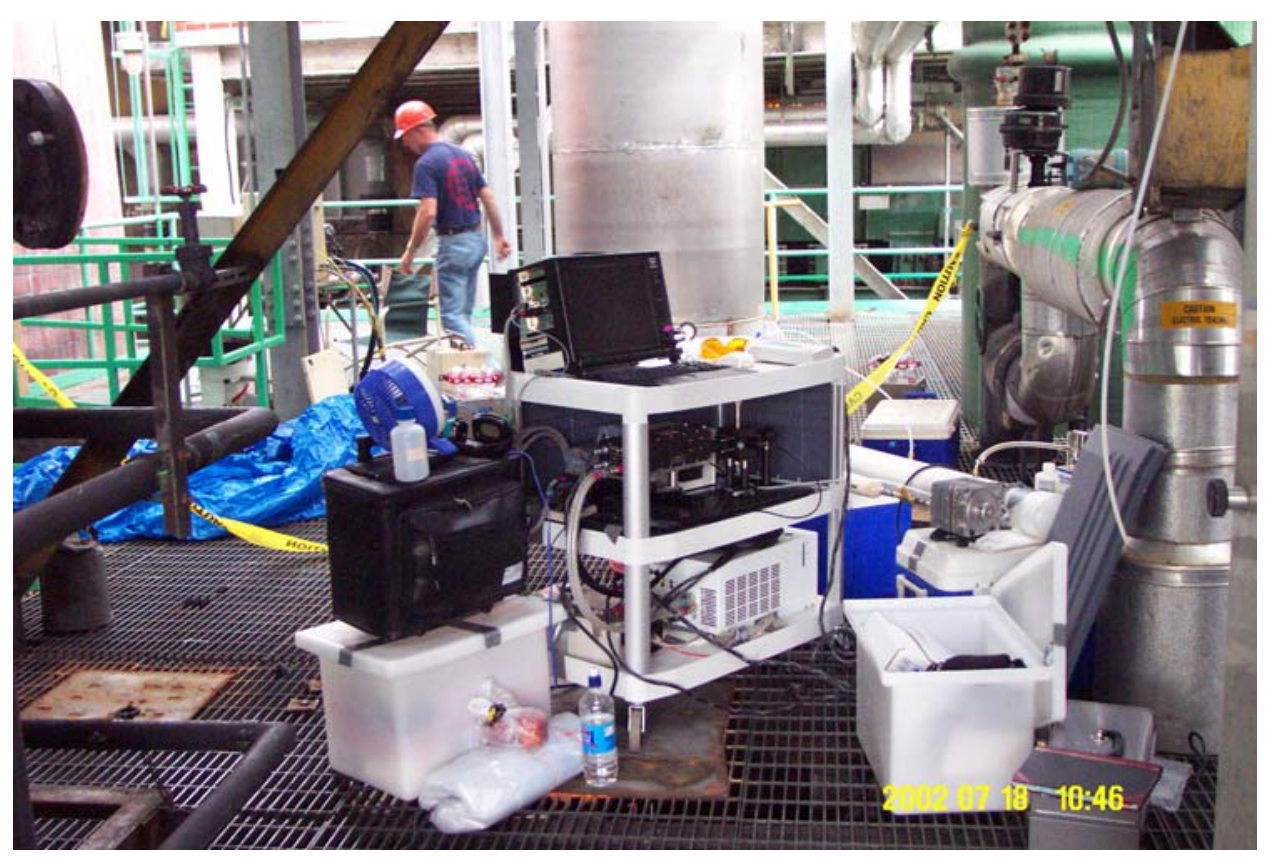

Another picture of the ABFLIPS prototype unit.

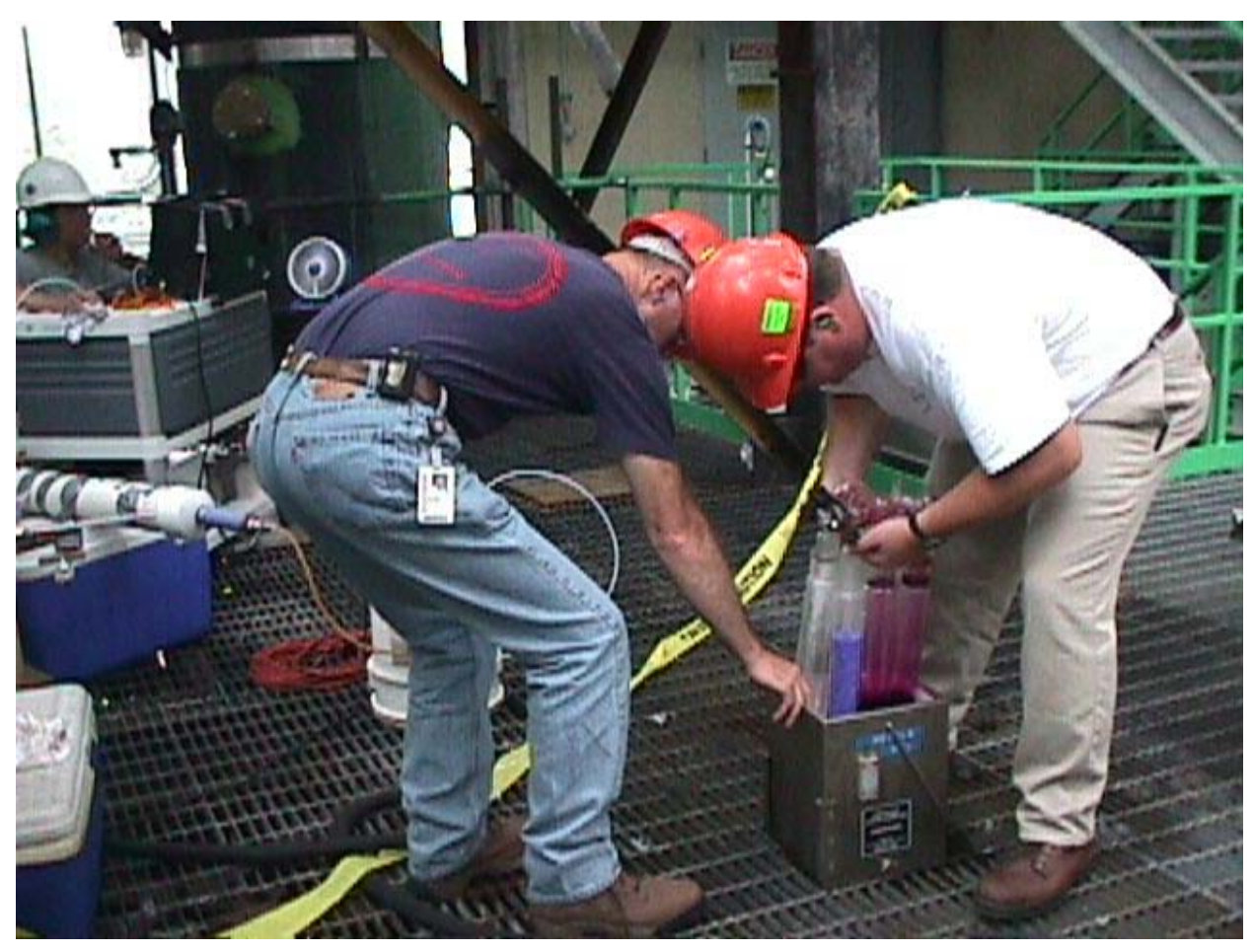

Eastman staff unloading the sampling train after one experiment. 


\section{INTERNAL DISTRIBUTION}

1-3. M. D. Cheng

4. T. O. Early

5. S. G. Hildebrand
6-7. ESD Library

8. ORNL Central Research Library

9. ORNL Laboratory Records-RC

\section{EXTERNAL DISTRIBUTION}

10. R. W. Vannice, Eastman Chemical Company, Eastman Road, Kingsport, TN 37660

11. R. Strang, Eastman Chemical Company, Eastman Road, Kingsport, TN 37660

12. J. Evans, Eastman Chemical Company, Eastman Road, Kingsport, TN 37660

\section{ELECTRONIC NOTIFICATION}

13. L. I. Croff, Technology Transfer and Economic Development, ORNL (croffli@ornl.gov)

14. R. Holst, SERDP Program Office, Arlington, VA (robert.holst@osd.mil)

15. B. Harre, Naval Facilities of Engineering Services, Port Hueneme, CA (harrebl@nfesc.navy.mil) 